\title{
Identification and characterization a novel polar tube protein (NbPTP6) from the microsporidian Nosema bombycis
}

\author{
Qing LV ${ }^{1,2}$, Lijun Wang ${ }^{1,2}$, Youpeng Fan 1,2, Xianzhi Meng ${ }^{1,2}$, Keke Liu ${ }^{1,2}$, Bingqian Zhou ${ }^{1,2}$, Jie Chen ${ }^{1,2}$, \\ Guoqing Pan ${ }^{1,2^{*}}$, Mengxian Long ${ }^{1,2^{*}}$ and Zeyang Zhou ${ }^{1,2,3}$
}

\begin{abstract}
Background: Microsporidians are opportunistic pathogens with a wide range of hosts, including invertebrates, vertebrates and even humans. Microsporidians possess a highly specialized invasion structure, the polar tube. When spores encounter an appropriate environmental stimulation, the polar tube rapidly everts out of the spore, forming a 50-500 $\mu \mathrm{m}$ hollow tube that serves as a conduit for sporoplasm passage into host cells. The polar tube is mainly composed of polar tube proteins (PTPs). So far, five major polar tube proteins have been isolated from microsporidians. Nosema bombycis, the first identified microsporidian, infects the economically important insect silkworm and causes heavy financial loss to the sericulture industry annually.

Results: A novel polar tube protein of N. bombycis (NbPTP6) was identified. NbPTP6 was rich in histidine $(\mathrm{H})$ and serine (S), which contained a signal peptide of 16 amino acids at the N-terminus. NbPTP6 also had 6 potential O-glycosylation sites and 1 potential N-glycosylation site. The sequence alignment analysis revealed that NbPTP6 was homologous with uncharacterized proteins from other microsporidians (Encephalitozoon cuniculi, E. hellem and N. ceranae). Additionally, the NbPTP6 gene was expressed in mature N. bombycis spores. Indirect immunofluorescence analysis (IFA) result showed that NbPTP6 is localized on the whole polar tube of the germinated spores. Moreover, IFA, enzyme-linked immunosorbent (ELISA) and fluorescence-activated cell sorting (FACS) assays results revealed that NbPTP6 had cell-binding ability.
\end{abstract}

Conclusions: Based on our results, we have confirmed that NbPTP6 is a novel microsporidian polar tube protein. This protein could adhere with the host cell surface, so we speculated it might play an important role in the process of microsporidian infection.

Keywords: Nosema bombycis, Novel, Polar tube protein, Localization, Cell-binding ability

\section{Background}

Microsporidians are obligate, intracellular, spore-forming parasites and currently considered as a kind of fungi [1-4]. Since the discovery of the first microsporidian Nosema bombycis from silkworms in the 19th century,

*Correspondence: gqpan@swu.edu.cn; longmx@swu.edu.cn ${ }^{1}$ State Key Laboratory of Silkworm Genome Biology, Southwest University, Chongqing 400715, China

Full list of author information is available at the end of the article there are some microsporidians that infect immunocompromised humans such as Encephalitozoon hellem (Eh), E. cuniculi $(\mathrm{Ec})$ and Enterocytozoon bieneusi $(\mathrm{Eb})[1,5]$; other microsporidians are insect pathogens such as $N$. bombycis (Nb), N. ceranae (Nc), and Antonospora locustae (Al) [6-8]. Although microsporidians differ in host range and specificity, they all utilize a similar infection mechanism. Under a certain external stimulation, the highly specialized polar tube is everted from the spore, 
forming a hollow tube that delivers the infectious sporoplasm into its host cell's cytoplasm [1, 9-11]. However, due to the small size of the spores $(1-10 \mu \mathrm{m})$, the small diameter of the polar tube $(0.1-0.2 \mu \mathrm{m})$, and the rapidity of polar tube everting and sporoplasm passage $(<2 \mathrm{~s})$, the study of the polar tube extrusion process is difficult [6-8, $12,13]$.

The polar tube is composed of proteins, and presently, five kinds of polar tube proteins (PTP1-PTP5) have been identified from different microsporidia. PTP1, a proline-rich protein, contains many cysteine residues in its $\mathrm{N}$-terminal and $\mathrm{C}$-terminal domains. PTP1 is an $\mathrm{O}$-mannoglycosylated protein that presumably binds to host sugar receptors to promote microsporidian infection $[8,11,14,15]$. Interestingly, PTP2 is found at the same genomic locus with PTP1 [14]. Despite a high sequence divergence, various PTP2 proteins share common characteristics, such as the protein molecular weight, basic isoelectric point (pI) and high lysine content. The conservation cysteine residues of PTP2 are most likely involved in intra- and/or inter-protein disulfide bridges [15-18]. The third polar tube protein, PTP3, is identified from an E. cuniculi cDNA library. PTP1, PTP2 and PTP3 have been demonstrated to interact with each other by yeast two-hybrid assays $[19,20]$. Two new PTPs (PTP4 and PTP5) have been identified from the polar tube by proteomics and antibody-based approaches [21, 22]. Recently, transferrin receptor 1 (TfR1) was identified as a potential host cell receptor of EhPTP4, and the microsporidian infection rate in TfR1-knockout mutant host cells was markedly reduced [23].

In this study, we identified a novel polar tube protein from $N$. bombycis named as NbPTP6. The specific polyclonal antibody of this protein labeled the whole polar tube of geminated spores. Furthermore, this polar tube protein could bind with the surface of host cells, suggesting it might play an important role in the process of $N$. bombycis infection.

\section{Methods}

\section{Sequence analysis}

NbPTP6 was screened from the proteomic data of germinated spores (Additional file 1: Figure S1; Additional file 2: Table S1). To further identify and functionally characterize NbPTP6, protein conserved domains were predicted by online tool (http://smart.emblheidelberg. de/index2.cgi). The signal peptide was predicted by SignalP (http://www.cbs.dtu.dk/services/SignalP/). Multiple sequence alignment was generated with ClustalX1.83 [24] and phylogenetic relationships were assessed with MEGA5 program [24]. The phosphorylation site was predicted using the SCANPROSITE tool (http://prosi te.expasy.org/prosite.html). NETNGLYC (http://www.
cbs.dtu.dk/services/NetNGlyc/) and NETOGLYC (http:// www.cbs.dtu.dk/services/NetOGlyc/) were used to analyze $\mathrm{N}$ - and $\mathrm{O}$-glycosylation sites, respectively. The secondary structure of the protein was predicted by using the Jpred 4 tool (http://www.compbio.dundee.ac.uk/ jpred/).

\section{RNA extraction and semi-quantitative reverse transcription polymerase chain reaction (sqRT-PCR)}

The sqRT-PCR was applied to detect the transcription level of the NbPTP6 gene. Fifth-instar silkworms were infected with $1 \times 10^{4} / \mathrm{ml}$ virulent $N$. bombycis. The midgut of infected and control silkworms were collected at 1-7 days post-infection. The total RNA was extracted and reverse-transcribed into cDNA using reverse transcription kit (Promega, Shanghai, China). PCR primers were designed by Primer Premier 5.0 (Table 1) according to the NbPTP6 gene (GenBank: KB910042) and $\beta$-tubulin gene (GenBank: ABG54480.1). PCR conditions were as follows: $95^{\circ} \mathrm{C}$ for $5 \mathrm{~min}, 30$ cycles of $95{ }^{\circ} \mathrm{C}$ for $40 \mathrm{~s}, 55^{\circ} \mathrm{C}$ for $40 \mathrm{~s}$ and $72{ }^{\circ} \mathrm{C}$ for $1 \mathrm{~min}$.

\section{Cloning, expression, purification of recombinant NbPTP6 and preparation of antiserum against NbPTP6}

Primers for NbPTP6 cloning were designed without signal peptide, as shown in Table 1 . The amplified DNA fragment without signal peptide of NbPTP6 (693 bp) was inserted into pMD19-T vector for sequencing and subcloned into pET32a $(+)$ plasmid. The recombinant plasmid was transformed into Escherichia coli strain BL21 (DE3) for prokaryotic expression. Cells were cultured and induced at $37^{\circ} \mathrm{C}$ with $0.2 \mathrm{M} \mathrm{IPTG}$ for $4 \mathrm{~h}$, then the recombinant proteins were purified using a Ni-NTA affinity chromatography column (Qiagen, Beijing, China). Mice were immunized with rNbPTP6 protein mixed with Freund's adjuvant (1:1; Sigma-Aldrich, St. Louis, USA). After four immunizations at intervals of 7 days, antiNbPTP6 serum was obtained and stored at $-20^{\circ} \mathrm{C}$.

\section{Western blot analysis}

The extraction method of total spore protein of mature spores was referred by Liu et al. [21]. Concisely, spores $\left(1 \times 10^{9}\right.$ spores $\left./ \mathrm{ml}\right)$ were disrupted 5 min for 3 times with $0.4 \mathrm{~g}$ acid-washed glass beads $(0.2 \mathrm{~g}, 212-300 \mu \mathrm{m} ; 0.2 \mathrm{~g}$, 425-600 $\mu \mathrm{m}$; Sigma-Aldrich) in $500 \mu \mathrm{l}$ buffer PBS (pH 7.4), then centrifuged at $12,000 \times \mathrm{rpm}$ for $5 \mathrm{~min}$ at $4{ }^{\circ} \mathrm{C}$. The supernatant was collected as the total spore protein [24]. For immunoblotting analysis, total spore protein was separated by $12 \%$ SDS-PAGE and transferred to a PVDF membrane (Roche, Shanghai, China). The membrane was incubated with mouse anti-NbPTP6 serum (diluted 1:500 in blocking solution) for $1 \mathrm{~h}$ at $37^{\circ} \mathrm{C}$. The 
anti-Trx-Tag mouse monoclonal antibody (1:1000 dilution; Sangon Biotech, Shanghai, China) was used as a negative control. Then the membrane was washed and incubated with anti-mouse $\lg$ secondary antibody (1:8000 dilution; Sigma-Aldrich) for $1 \mathrm{~h}$ at $37{ }^{\circ} \mathrm{C}$. The blot was developed with ECL western blot detection kit (Thermo Fisher Scientific, Shanghai, China).

\section{Immunofluorescence analysis (IFA)}

Purified mature spores were added on poly-lysine coated slides and dried at room temperature for $30 \mathrm{~min}$. Then, spores were germinated in $0.1 \mathrm{M} \mathrm{KOH}$ for $40 \mathrm{~min}$ at $30{ }^{\circ} \mathrm{C}$, fixed in $4 \%$ formaldehyde at room temperature for $30 \mathrm{~min}$, washed and blocked with $10 \%(\mathrm{v} / \mathrm{v})$ non-specific goat serum together with $5 \%(\mathrm{w} / \mathrm{v})$ bovine serum albumin (BSA) in PBST for $1 \mathrm{~h}$ at room temperature. Then, samples were simultaneously incubated with mouse antiNbPTP6 (1:100 dilution) and rabbit anti-NbPTP1 (1:200 dilution) serum at room temperature for $1 \mathrm{~h}$. Meanwhile, the anti-Trx-Tag mouse monoclonal antibody was used as a negative control. After washing three times, samples were incubated with Alexa Fluor ${ }^{\circledR} 594$ conjugate goat anti-rabbit IgG (1:1000 dilution; Thermo Fisher Scientific) and Alexa Fluor ${ }^{\circledR} 488$ conjugate goat anti-mouse IgG (1:1000 dilution; Thermo Fisher Scientific) for $1 \mathrm{~h}$ at room temperature. After washing with PBST, samples were stained with DAPI (1:1000 dilution; Thermo Fisher Scientific) for $20 \mathrm{~min}$ and examined under an Olympus FV1200 laser confocal microscope (Olympus, Tokyo, Japan).

To detect the binding of NbPTP6 by IFA, BmE cells were grown in 12-well plates and fixed with $4 \%$ paraformaldehyde in PBS for $30 \mathrm{~min}$ at room temperature, washed and blocked with $10 \%(\mathrm{v} / \mathrm{v})$ non-specific goat serum together with $5 \%(\mathrm{w} / \mathrm{v})$ bovine serum albumin (BSA) in PBST for $1 \mathrm{~h}$ at room temperature. After washing three times with PBST, rNbPTP6 protein was added to the well and incubated at $37{ }^{\circ} \mathrm{C}$ for $1 \mathrm{~h}$. The pET-32a (+) nonload protein at the same concentration as rNbPTP6 was used as a negative control for these assays. After washing three times with PBST, samples were incubated with a commercial His-tag mouse monoclonal antibody (1:1000 dilution; Sigma-Aldrich) at room temperature for $1 \mathrm{~h}$. After washing three times, the samples were incubated with Alexa Fluor ${ }^{\circledR} 488$ conjugate goat anti-mouse IgG (1:1000 dilution; Thermo Fisher Scientific) for $1 \mathrm{~h}$ at room temperature. After washing with PBST, samples were stained with DAPI (1:1000 dilution; Thermo Fisher Scientific) for $20 \mathrm{~min}$ and examined under an Olympus FV1200 laser confocal microscope (Olympus).

\section{ELISA binding assay}

Embryonic cells of Bombyx mori (BmE cells) were grown in 96-well plates and fixed with $4 \%$ paraformaldehyde in PBS for $30 \mathrm{~min}$ at room temperature. Non-specific binding sites were blocked by incubating with 3\% BSA in TBST buffer. After washing three times with TBST, different concentration of the rNbPTP6 protein was added to each well and incubated at $37^{\circ} \mathrm{C}$ for $1 \mathrm{~h}$. The plates were washed three times with TBST, and fixed by incubating with methanol for $10 \mathrm{~min}$. After washing with TBST three times, a commercial His-tag mouse monoclonal antibody (1:1000 dilution; Sigma-Aldrich) was added to cell plates and incubated at room temperature for $1 \mathrm{~h}$, and the cells were washed three times with TBST. Then, anti-mouse lgG secondary antibody (1:8000 dilution; Sigma-Aldrich) was added to cell plates and incubated at room temperature for $1 \mathrm{~h}$, and the cells were washed three times with TBST. The pET-32a $(+)$ non-load protein was used as a negative control. O-diaminobenzene (Sigma-Aldrich), as a kind of reaction substrate, was added to the plate at $37^{\circ} \mathrm{C}$ for $15 \mathrm{~min}$, then $\mathrm{OD}_{450}$ was detected using a Tecan microplate reader (Tecan, Shanghai, China).

\section{Fluorescence-activated cell sorting FACS assays}

BmE cells $\left(1 \times 10^{7}\right)$ were washed three times with PBS buffer. rNbPTP6 protein $(0.5 \mathrm{~g} / \mathrm{ml})$ was incubated with BmE cells at $37{ }^{\circ} \mathrm{C}$ for $1 \mathrm{~h}$, washed three times, then blocked with $10 \%(\mathrm{v} / \mathrm{v})$ non-specific goat serum together with $5 \%(\mathrm{w} / \mathrm{v}) \mathrm{BSA}$ in PBST at $37^{\circ} \mathrm{C}$ for $1 \mathrm{~h}$. After washing three times, the commercial His-tag mouse monoclonal

Table 1 Oligonucleotide primers for this study

\begin{tabular}{llll}
\hline Gene name & Primer name & Primer sequence $\left(5^{\prime}-3^{\prime}\right)$ & Fragment length (bp) \\
\hline NbPTP6 (for cloning) & NbPTP6_F & CGCGGATCCGAGCAGTTTAAACTTAAACA & 693 \\
& NbPTP6_R & CCGCTCGAGTTATTGATTCATAAAATTCA & 741 \\
NbPTP6 (for sqRT-PCR) & NbPTP6_F & ATGAATTAATAATGATTA & 737 \\
$\beta$-tubulin & NbPTP6_R & TTATTGATTCATAAAATTC & \\
& $\beta$-tubulin_F & ATGAGAGAAATTATTCACTT & TTAATTTCCCATATAATCCC \\
\hline
\end{tabular}


antibody (1:1000 dilution; Sigma-Aldrich) was incubated with cells for $1 \mathrm{~h}$ at $37^{\circ} \mathrm{C}$ then washed with PBST three times. Cells were then incubated with Alexa Fluor ${ }^{\circledR} 488$ conjugate goat anti-mouse IgG (1:1000 dilution; Thermo Fisher) at room temperature for $1 \mathrm{~h}$. After washing three times, cell samples were examined using a flow cytometer (Beckman Coulter, Brea, USA). The pET-32a (+) nonload protein was used as a negative control.

\section{Results}

\section{Sequence characteristics of NbPTP6}

NbPTP6 gene is 741 bp in length and encodes a 247amino acid (aa) protein, which has a calculated molecular weight of $28.3 \mathrm{kDa}$ and a predicted pI of 7.26. The sequence is rich in histamine and has a signal peptide consisting of 16 amino acids at the N-terminal. Moreover, it has 6 potential O-glycosylation sites and 1 potential $\mathrm{N}$-glycosylation site. The phosphorylation prediction result showed that NbPTP6 has 18 Ser phosphorylation sites, $8 \mathrm{Thr}$ phosphorylation sites and 7 Tyr phosphorylation sites. The protein has a simple helix structure, which is similar to the structure of the known polar tube proteins. However, there is no specific known conserved domain in NbPTP6. The phylogenetic tree showed that the NbPTP6 protein is closely related to a certain unknown protein of $N$. ceranae. More interestingly, NbPTP6 and homologous proteins of other microsporidians were in the same clade (Fig. 1a). The following NbPTP6 homologous protein sequences were found: from E. cuniculi (AEWD_081700; 26\% identity); E. hellem (EHEL_081670; 24\% identity); N. ceranae (NCER_100577; 27\% identity); $E$. romaleae (EROM_081710; 28\% identity); E. intestinalis (Eint_081680; 37\% identity); V. culicis (VCUG_01246; 33\% identity); and S. lophii (SLOPH_1767; 26\% identity) (Fig. 1b).

\section{Transcription and translation of NbPTP6}

To investigate the transcription level of NbPTP6, total mRNA from the midgut of infected silkworms at 1-7 dpi was extracted respectively. The sqRT-PCR results shown in Fig. 2 indicate that NbPTP6 was transcribed in $N$. bombycis-infected silkworms from 1 to $7 \mathrm{dpi}$ (Fig. 2a). Western blot analysis indicated that a unique band (30
$\mathrm{kDa}$ ) was detected in the total spore protein of $\mathrm{N}$. bombycis, which is consistent with the theoretical molecular weight of NbPTP6 (Fig. 2b).

\section{Immunolocalization of NbPTP6}

We used germinated spores to study the localization of NbPTP6 in $N$. bombycis. The IFA result revealed that anti-NbPTP6 serum labeled green fluorescence of Alexa488 dye was localized on the whole polar tube, and antiNbPTP1 serum labeled red fluorescence of Alexa-594 dye was also localized on the whole polar tube. Interestingly, the signal of anti-NbPTP6 serum and anti-NbPTP1 serum could completely merge together (Fig. 3b). The nuclei of $N$. bombycis spores were labelled for blue fluorescence with DAPI. After germination, the spore nuclei were ejected out of spores, so there was no blue signal in the empty spore shells. For the negative control group, no green fluorescence was detected by native mouse serum (Fig. 3a). In addition, by IEM, gold particles-labeled NbPTP6 antibody were distributed mainly in the polar tube region of spores (Additional file 3: Figure S2a1); however, no gold particles-labeled Trx-tag antibody was detected in the negative-control (Additional file 3: Figure S2a2). Therefore, these data confirmed that NbPTP6 is a novel polar tube protein of $N$. bombycis.

\section{Cell binding ability analysis of NbPTP6}

In order to explore the role of NbPTP6 in N. bombycis infection, we conducted a preliminary study on its host cell binding ability. First, IFA was used to test the hypothesis of the cell binding ability of NbPTP6. The purified rNbPTP6 protein was incubated with BmE cells. The green fluorescence from Alexa-488 dye labeled the commercial His-tag antibody was shown around the $\mathrm{BmE}$ cell, revealing that NbPTP6 could bind with the surface of BmE cells (Fig. 4a1). But in the control group, there was no green fluorescence (Fig. 4a2). Then, we further employed an ELISA to verify the cell-binding ability of NbPTP6, and the result showed that with the increase of protein concentration, the cell-binding ability of NbPTP6 became stronger, suggesting that NbPTP6 most likely interacts with a protein (or other binding partner) on the host cell membrane (Fig. 4b). Finally, we used FACS assays to further verify this hypothesis and found that

\footnotetext{
(See figure on next page.)

Fig. 1 Alignment and phylogenetic tree of multiple NbPTP6 homologous sequences in various microsporidia, fungi and bacteria. a Phylogenetic tree of multiple NbPTP6 homologous sequences. Neighbour-joining tree was constructed using MEGA 5 software. The amino acid sequences were obtained from Uniprot: E. cuniculi (AEWD_081700); E. hellem (EHEL_081670); N. ceranae (NCER_100577); V. culicis (VCUG_01246); Spr. lophii (SLOPH_1767); N. bombycis (NBO_1135g0001); E. romaleae (EROM_081710); E. intestinalis (Eint_081680); Smi. culicis (AYI70_g11826); P. brasiliensis (PADG_06126); and Ser. vermifera (M408DRAFT_280892). b Alignment of NbPTP6 homologous sequences. The red shades highlight identical amino acids; the red underline indicates the predicted signal peptide of NbPTP6; the blue and green triangles represent O-glycosylation sites and $\mathrm{N}$-glycosylation sites of NbPTP6, respectively
} 


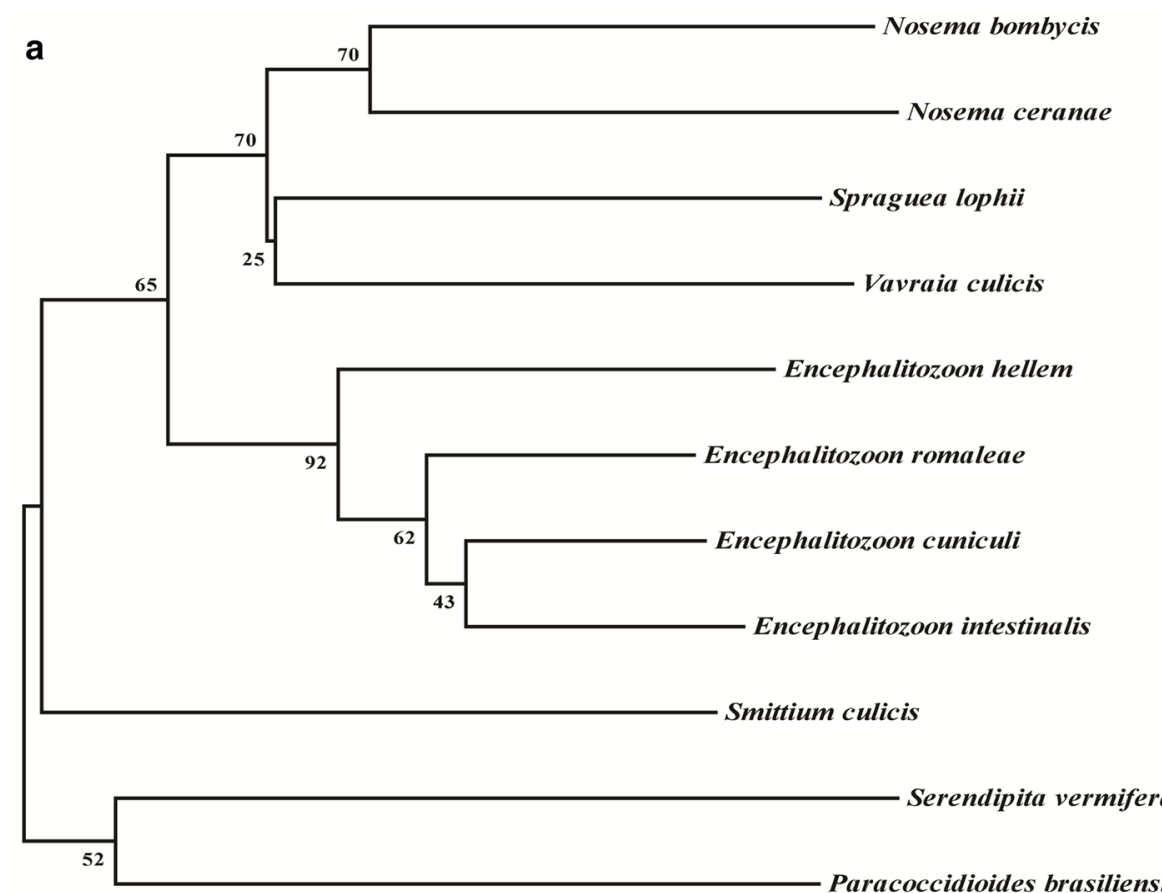

\section{Microsporidia}

Fungi

Paracoccidioides brasiliensis

\section{2}

b

NBO $1135 \mathrm{~g} 0001$ NCER_100577 NCER_100577 EHEL_081670 AEWD_081700 EROM_081710 Eint_081680 SLOPH 1767 VCUG_01246 1 10 MKL T M I T 20 MR . KTAIEQLIKT ISGES 等 MRLIALCMMVVLE .................................

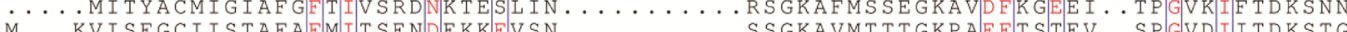

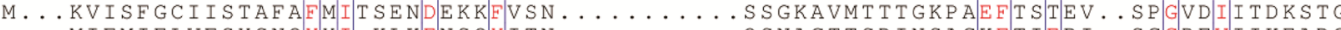

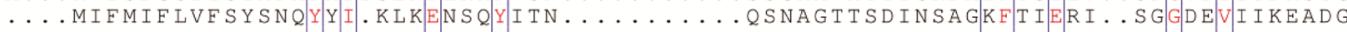
$\ldots \ldots$ MFVYLVSLLAFREL.KRIDRDTIIGQ . . . . . . . . . . SNGNITFVDPDEADIE LENTDHPNEDFUMVRSKDN

\section{0}

90

100

110

120

130

140

NBO_1135g000 NCER_100577 EHEL_081670 AEWD 081700

EROM_081710

Eint 081680

SLOPH 1767

SLOPH_1767

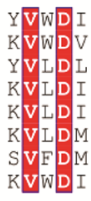

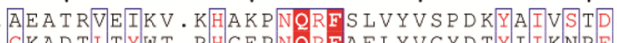

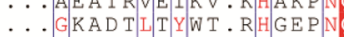
$\begin{array}{llllll} & \end{array}$ .. EGSRTNITFYA.RHG . . AF LYVGYDTYI I I K N R R E E I G GNMKD G Y T I I K N N E D.

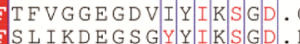

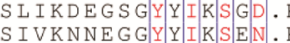
TIRLEGYRDY S I R R D N

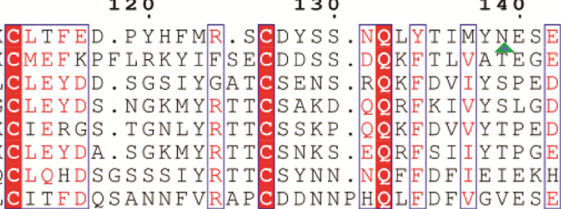
150

160 170 180

NBO_1135g0001 NCER 100577 EHEL_081670 EHEL_081670 AEWD_081700 EROM_081710 Eint_081680
SLOPH_1767 VCUG_01246

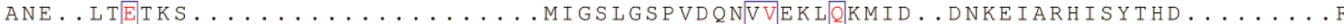

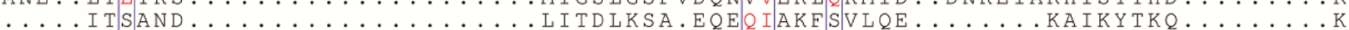

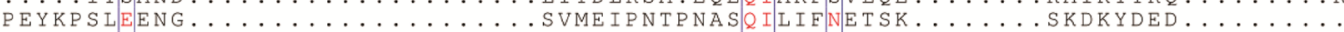

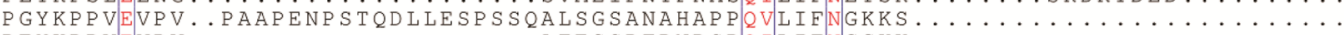

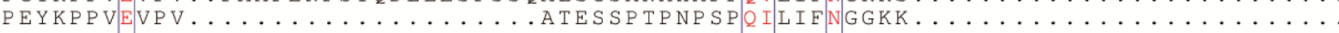

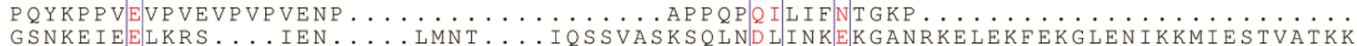

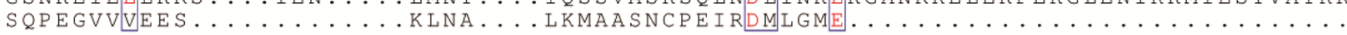

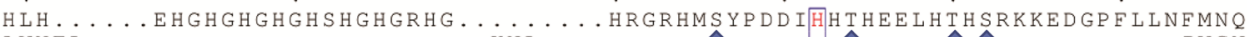
AVNFL $\ldots \ldots \ldots \ldots \ldots \ldots \ldots \ldots \ldots \ldots \ldots \ldots \ldots$

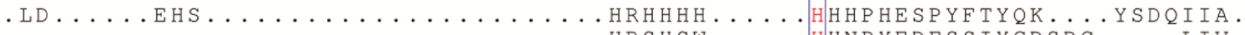
$\ldots \ldots \ldots \ldots \ldots \ldots \ldots \ldots \ldots \ldots \ldots$ HRHSW $\ldots \ldots \ldots$ H $\ldots \ldots \ldots$ H

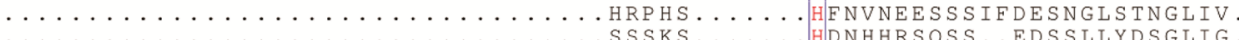
QLNEIKCEIEHTLNTKSSITDI

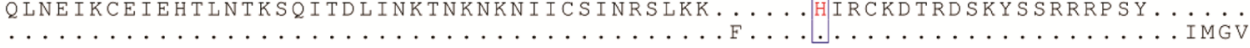




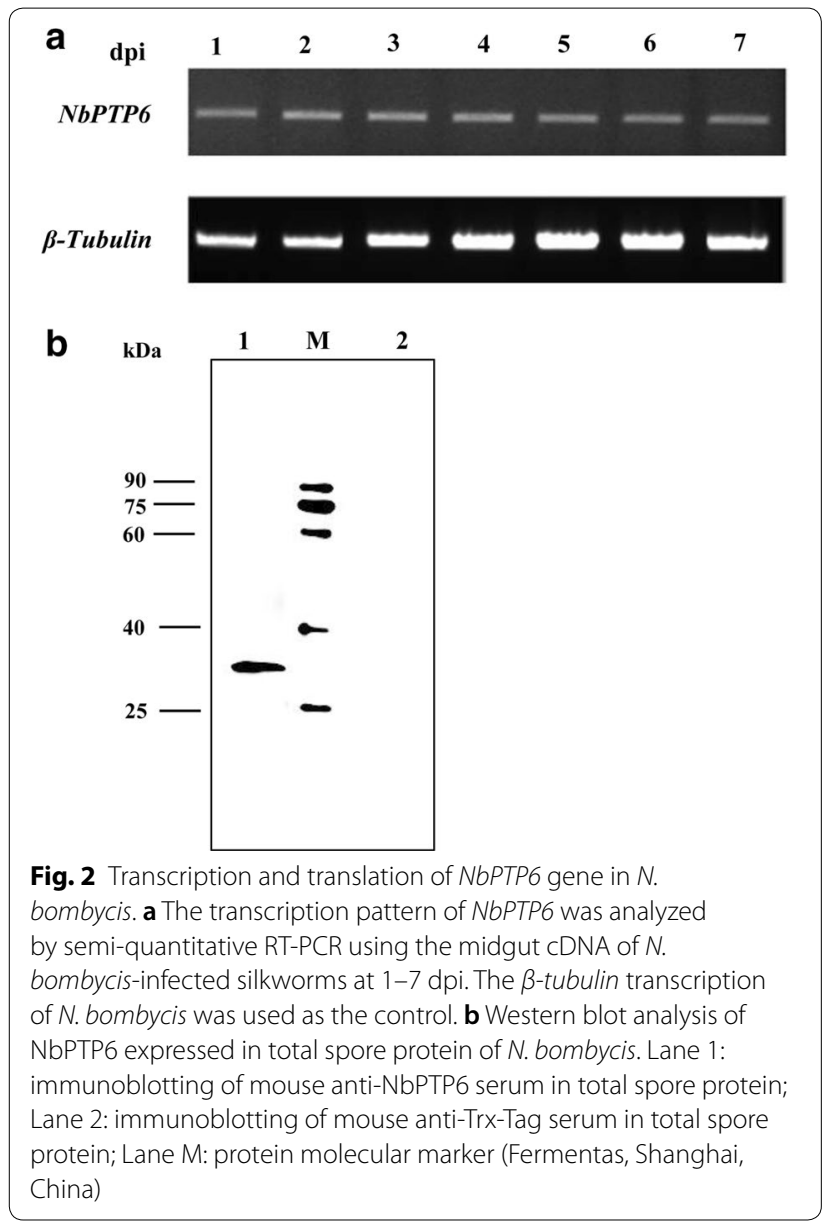

the fluorescence intensity of the rNbPTP6 protein-bound cells was distinctly higher than the control group cells (Fig. 4c).

\section{Discussion}

Microsporidians possess a unique invasion apparatus, the polar tube. Under the appropriate environmental stimulation, the polar tube can evert rapidly out of the microsporidian spore, form a hollow tube and serve as a conduit for the passage of sporoplasm and nuclear material into a new host cell $[6,7,25]$. Within the spore, the polar tube is filled with unpolymerized polar tube proteins. After germination, the length of the everted polar tubes is approximately 2-3 times longer than that of the coiled tubes inside spores, so it has been hypothesized that unpolymerized polar tube proteins are incorporated at the growing tip of the polar tube during everting or that the tube unfolds during eversion $[1,2,25]$. In this study, NbPTP6 was localized on the whole polar tube, which was the same as the localization of NbPTP1, NbPTP2 and NbPTP3. Based on these results, we determined that PTP6 is a novel polar tube protein of $N$. bombycis.

NbPTP6 had six potential O-glycosylation sites and one potential N-glycosylation site, which was similar to the NbPTP1 protein. Previously, O-glycosylation of EhPTP1 was found to affect the ability of E. hellem to infect host cells [26-28]. Moreover, NbPTP1 could bind with ConA, proving the existence of glycosylation modification $[1,23$, $28,29]$. It was speculated that it might play an important role in protecting the polar tube from the host intestinal digestion, or in interacting with the mannose receptor on the host cell membrane to promote infection and adhesion of the polar tube to the host cell membrane $[1,23$, 29].

Previous studies found that the polar tube is surrounded by the host cell membrane at the invasion site. And polar tube does not pierce or break the host plasma membrane, instead it is pushing the host cell

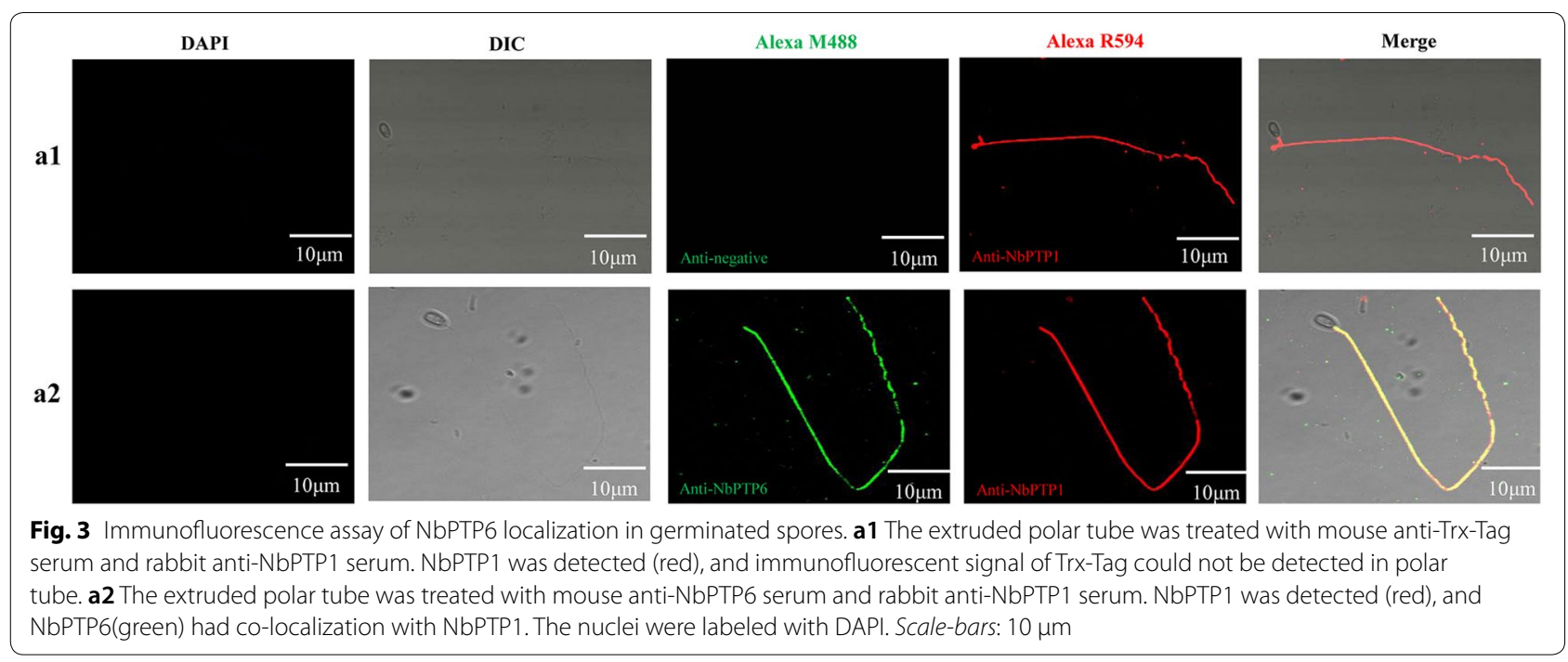




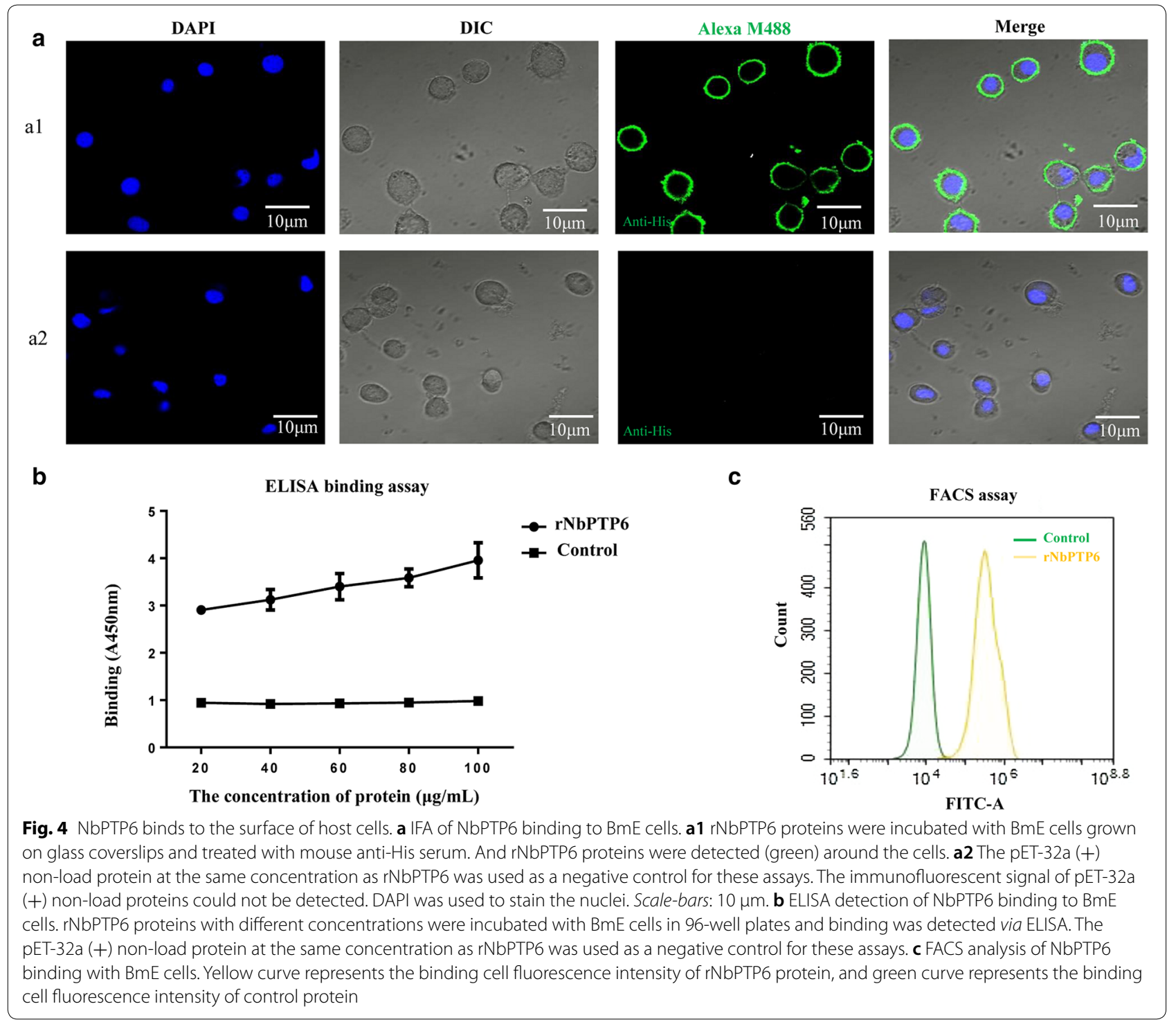

plasma membrane into the host cell creating a microenvironment into which the microsporidian sporoplasm is extruded from the end of the polar tube [30-33]. Therefore, it was suggested there was an interaction between the polar tube and host cell membrane. In previous research, PTP4 from E. hellem had the ability to adhere with cells and TfR1 was identified as a potential host cell interacting receptor for EhPTP4. The infection rate of $E$. hellem was significantly reduced when TfR 1 recombinant protein or anti-TfR 1 antibody was added into the cell culture [23]. These results indicated that PTP4 is an important protein of the polar tube involved in the host cell infection mechanism of microsporidians. In our study, IFA, ELISA and FACS results confirmed that NbPTP6 could bind with host BmE cells, which was similar with EhPTP4. So we speculated that there were interaction receptors of NbPTP6 on the surface of host cells to facilitate microsporidian infection. We plan to screen and identify the potential host cell receptor of NbPTP6.

\section{Conclusions}

In summary, we have identified a novel polar tube protein identified in the microsporidium $N$. bombycis. NbPTP6 was localized on the polar tube, and it has 
been shown to bind with the surface of host cells. It was helpful to understand the composition of polar tube and the infection mechanism of microsporidia.

\section{Supplementary information}

Supplementary information accompanies this paper at https://doi. org/10.1186/s13071-020-04348-z.

Additional file 1: Figure S1. SDS-PAGE analysis the protein of germinated spores.

Additional file 2: Table S1. The top 20 proteins identified in the proteomic data of germinated spores.

Additional file 3: Figure S2. IEM analysis of NbPTP6 localization in microsporidian spores. a1 Mature N. bombycis spore, with gold particles labeled NbPTP6 antibody localized mainly to the polar tube region. The inset shows an enlarged section of the image. a2 Negative control. Arrowheads mark colloidal gold particles. Scale-bar: 500 nm. Abbreviations: En, endospore; Ex, exospore; PT, polar tube.

\section{Abbreviations}

PTPS: polar tube proteins; IFA: indirect immunofluorescence analysis; ELISA: enzyme-linked immunosorbent; FACS: fluorescence-activated cell sorting; sqRT-PCR: semi-quantitative reverse transcription polymerase chain reaction; BmE cells: embryonic cells of Bombyx mori; TfR1: transferrin receptor 1; IEM: immunoeletron microscopy.

\section{Acknowledgements}

The authors thank Dr. Maoshuang Ran and Yan Zhu who provided assistance with FACS analysis. Special thanks to Ms. Rong Wang for her help on the biological software analysis.

\section{Authors' contributions}

$\mathrm{QL}$ and MXL designed the project, performed the experiments, analyzed the data and drafted the manuscript. QL and LJW supervised and performed material collection, and all the other laboratory experiments. YPF gave input on method refinement. XZM provided great help in the IEM experiment. QL, $K K L$ and $B Q Z$ performed the bioinformatics analyses and manuscript preparation. MXL, JC, GQP and ZYZ provided overall study supervision. All authors read and approved the final manuscript.

\section{Funding}

This study was supported by grants from the National Natural Science Foundation of China (Grant No. 31402138), the Chongqing Foundation and Advanced Research Project (Grant No. cstc2018jcyjAX0550), and the Fundamental Research Funds for the Central Universities (Grant No. XDJK2018AA001).

\section{Availability of data and materials}

Data supporting the conclusions of this article are included within the article and its additional files. The raw data are available from the corresponding author upon reasonable request.

\section{Ethics approval and consent to participate}

The collection of microsporidian and silkworm specimens during the study was approved by the State Key Laboratory of Silkworm Genome Biology, Southwest University, Chongqing, China.

\section{Consent for publication}

Not applicable.

\section{Competing interests}

The authors declare that they have no competing interests.

\section{Author details}

1 State Key Laboratory of Silkworm Genome Biology, Southwest University, Chongqing 400715, China. ${ }^{2}$ Chongqing Key Laboratory of Microsporidia
Infection and Control, Southwest University, Chongqing 400715, China. ${ }^{3}$ College of Life Sciences, Chongqing Normal University, Chongqing 400047, China.

Received: 2 April 2020 Accepted: 5 September 2020

Published online: 15 September 2020

\section{References}

1. Han B, Weiss LM. Microsporidia: obligate intracellular pathogens within the fungal kingdom. Microbiol Spectrosc. 2017;5:22-30.

2. Xu Y, Weiss LM. The microsporidian polar tube: a highly specialised invasion organelle. Int J Parasitol. 2005;35:941-53.

3. Thomarat F, Vivarès CP, Gouy M. Phylogenetic analysis of the complete genome sequence of Encephalitozoon cuniculi supports the fungal origin of microsporidia and reveals a high frequency of fast-evolving genes. J Mol Evol. 2004;59:780-91.

4. Arisue N, Sánchez LB, Weiss LM, Müller M, Hashimoto T. Mitochondrialtype hsp70 genes of the amitochondriate protists, Giardia intestinalis, Entamoeba histolytica and two microsporidians. Parasitol Int. 2002;51:9-16.

5. Jaroenlak P, Boakye DW, Vanichviriyakit R, Williams BAP, Sritunyalucksana $\mathrm{K}$, Itsathitphaisarn O. Identification, characterization and heparin binding capacity of a spore-wall, virulence protein from the shrimp microsporidian, Enterocytozoon hepatopenaei (EHP). Parasit Vectors. 2018;11:177-9.

6. Purrini K, Weiser J. Ultrastructural study of the microsporidian chytridiopsis typographi (Chytridiopsida: Microspora) infecting the bark beetle, Ips typographus (Scolytidae: Coleoptera), with new data on spore dimorphism. J Invertebr Pathol. 1985;45:66-74.

7. Lom J. On the structure of the extruded microsporidian polar filament. Zeitsch Parasitenkde. 1972;38:200-13.

8. Weidner E. The microsporidian spore invasion tube. The ultrastructure, isolation, and characterization of the protein comprising the tube. J Cell Biol. 1976;71:23-34.

9. Li Z, Pan GQ, Li T, Huang W, Chen J, Geng LN, et al. SWP5, a spore wall protein, interacts with polar tube proteins in the parasitic microsporidian Nosema bombycis. Eukaryot Cell. 2012;11:229-37.

10. Takvorian PM, Han B, Cali A, Rice WJ, Gunther L, Macaluso F, et al. An ultrastructural study of the extruded polar tube of Anncaliia algerae (Microsporidia). J Eukaryot Microbiol. 2020;67:28-44.

11. Xu Y, Takvorian PM, Cali A, Orr G, Weiss LM. Glycosylation of the major polar tube protein of Encephalitozoon hellem, a microsporidian parasite that infects humans. Infect Immun. 2004;72:6341-50.

12. $X u Y$, , Takvorian $P$, Cali ANN, Weiss LM. Lectin binding of the major polar tube protein (ptp1) and its role in invasion. J Eukaryot Microbiol. 2003;50:600-1.

13. Bouzahzah B, Weiss LM. Glycosylation of the major polar tube protein of Encephalitozoon cuniculi. Parasitol Res. 2010;107:761-4.

14. Slamovits CH, Fast NM, Law JS, Keeling PJ. Genome compaction and stability in microsporidian intracellular parasites. Curr Biol. 2004;14:891-6.

15. Long MX, Tan YY, Yu B, Pan GQ, Zhou ZY. Expression of Nosema bombycis polar tube protein 1 in lepidopteran Sf9 cells and its effect on microsporidian proliferation. J Invertebr Pathol. 2020;172:107350.

16. Delbac F, Peuvel I, Metenier G, Peyretaillade E, Vivares CP. Microsporidian invasion apparatus: identification of a novel polar tube protein and evidence for clustering of ptp1 and ptp2 genes in three Encephalitozoon species. Infect Immun. 2001;69:1016-24.

17. Polonais V, Prensier G, Méténier G, Vivarès CP, Delbac F. Microsporidian polar tube proteins: highly divergent but closely linked genes encode PTP1 and PTP2 in members of the evolutionarily distant Antonospora and Encephalitozoon groups. Fungal Genet and Biol. 2005;42:791-803.

18. Polonais V, Belkorchia A, Roussel M, Peyretaillade E, Peyret P, Diogon M. Identification of two new polar tube proteins related to polar tube protein 2 in the microsporidian Antonospora locustae. FEMS Microbiol Lett. 2013;346:36-44.

19. Peuvel I, Peyret P, Méténier G, Vivarès CP, Delbac F. The microsporidian polar tube: evidence for a third polar tube protein (PTP3) in Encephalitozoon cuniculi. Mol Biochem Parasitol. 2002;122:69-80.

20. Bouzahzah B, Nagajyothi F, Ghosh K, Takvorian PM, Cali A, Tanowitz HB. Interactions of Encephalitozoon cuniculi polar tube proteins. Infect Immun. 2010;78:2745-53. 
21. Brosson D, Kuhn L, Delbac F, Garin J, Vivarès PC. Proteomic analysis of the eukaryotic parasite Encephalitozoon cuniculi (microsporidia): a reference map for proteins expressed in late sporogonial stages. Proteomics. 2006;6:3625-35.

22. Becnel JJ, Andreadis TG. Microsporidia in insects. Microsporidia. 2014:521-70.

23. Han B, Polonais V, Sugi T, Yakubu R, Takvorian PM, Cali A, et al. The role of microsporidian polar tube protein 4 (PTP4) in host cell infection. PLoS Pathog. 2017;13:e1006341.

24. Liu FY, Ma Q, Dang XQ, Wang Y, Song Y, Meng XZ, et al. Identification of a new subtilisin-like protease NbSLP2 interacting with cytoskeletal protein septin in Microsporidia Nosema bombycis. J Invertebr Pathol. 2017;148:110-7.

25. Corsaro D, Walochnik J, Venditti D, Steinmann J, Müller KD, Michel R. Microsporidia-like parasites of amoebae belong to the early fungal lineage Rozellomycota. Parasitol Res. 2014;113:1909-18.

26. Wang Y, Geng HX, Dang XQ, Xiang H, Li T. Comparative analysis of the proteins with tandem repeats from 8 microsporidia and characterization of a novel endospore wall protein colocalizing with polar tube from Nosema bombycis. J Eukaryot Microbiol. 2017:64:707-15.

27. Han B, Takvorian PM, Weiss LM. Invasion of host cells by microsporidia. Front Microbiol. 2020;11:172-4.
28. Taupin V, Garenaux E, Mazet M, Maes E, Denise H, Prensier G. Major O-glycans in the spores of two microsporidian parasites are represented by unbranched manno-oligosaccharides containing a-1,2 linkages. Glycobiology. 2006;17:56-67.

29. He Q, Luo J, Xu JZ, Meng XZ, Pan GQ, Li T. In-vitro cultivation of Nosema bombycis sporoplasms: a method for potential genetic engineering of microsporidia. J Invertebr Pathol. 2020;174:107420.

30. Bohne W, Böttcher K, Groß U. The parasitophorous vacuole of Encephalitozoon cuniculi: biogenesis and characteristics of the host cell-pathogen interface. Int J Med Microbiol. 2011;301:395-9.

31. Magaud A, Achbarou A, Desportes-Livage I. Cell invasion by the microsporidium Encephalitozoon intestinalis. J Eukaryot Microbiol. 1997;44:81-3.

32. Schottelius J, Schmetz C, Kock NP, Schüler T, Sobottka I, Fleischer B. Presentation by scanning electron microscopy of the life cycle of microsporidia of the genus Encephalitozoon. Microbes Infect. 2000;2:1401-6.

33. Bigliardi E, Sacchi L. Cell biology and invasion of the microsporidia. Microbes Infect. 2001;3:373-9.

\section{Publisher's Note}

Springer Nature remains neutral with regard to jurisdictional claims in published maps and institutional affiliations.
Ready to submit your research? Choose BMC and benefit from:

- fast, convenient online submission

- thorough peer review by experienced researchers in your field

- rapid publication on acceptance

- support for research data, including large and complex data types

- gold Open Access which fosters wider collaboration and increased citations

- maximum visibility for your research: over 100M website views per year

At BMC, research is always in progress.

Learn more biomedcentral.com/submissions 